\title{
دراسة اقتصادية لأهم المتغيرات الاقتصادية المؤثرة علي دعم رغيف الخبز المصري
}

\author{
محمد أحمد أحمد السبا
}

قسم الاقتصاد والتتمية الريفية، كلية العلوم الزراعية البيئية، جامعة العريش

Received: Mar. 19, 2017

Accepted: Mar. 23, 2017

الملخص:

تعتبر قضية الدعم أحد القضايا التي تهتم بها العديد من الدول باختلاف أنظمتها السياسية والاجتماعية والاقتصادية،

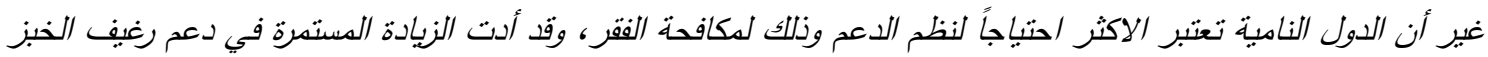

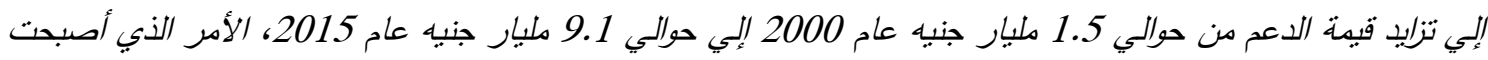

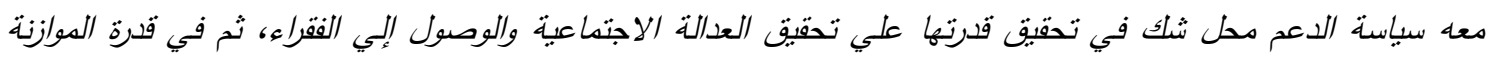

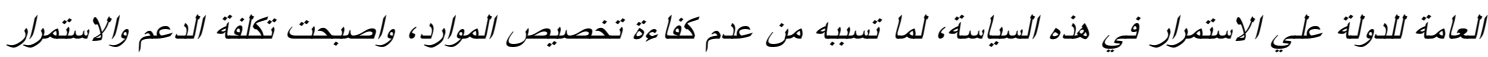

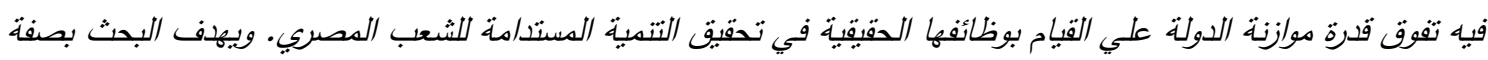

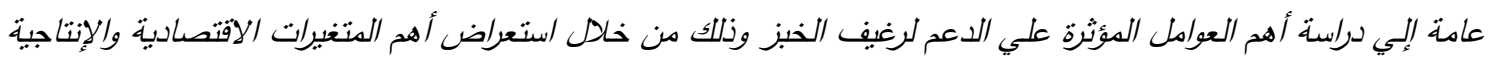

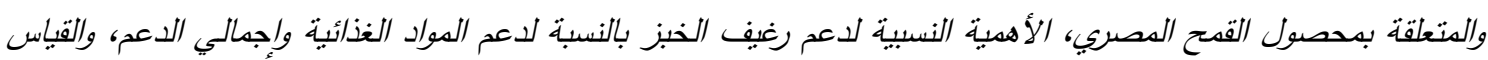

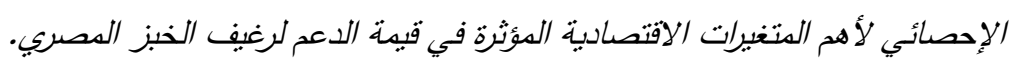

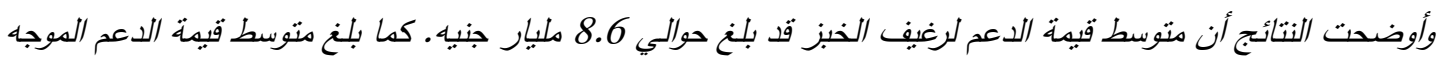

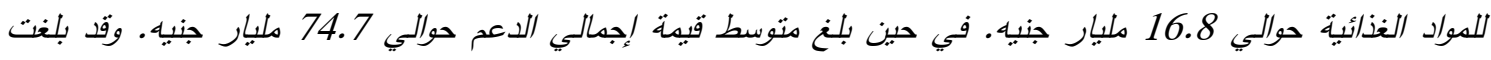

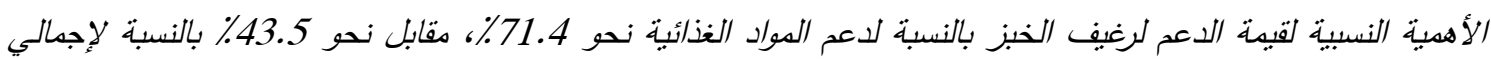

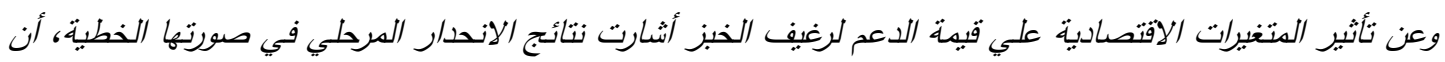

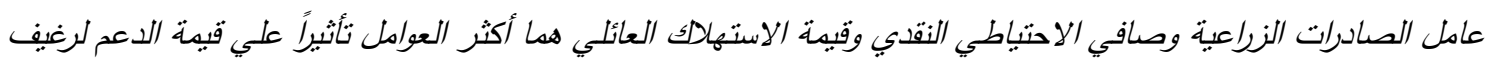

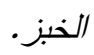
قد أظهرت نتائج الصورة النصف اللوغاريتمبة أن سعر الخصم يحتل المرتبة الأولي من حبث التأثير علي قبيمة الدعم

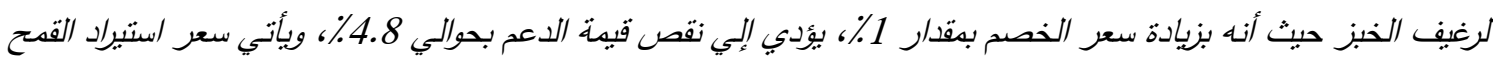

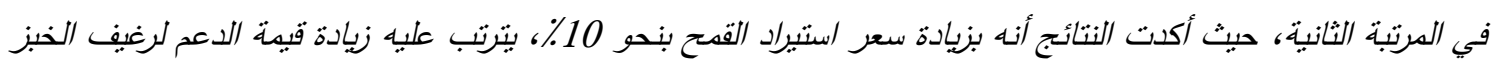

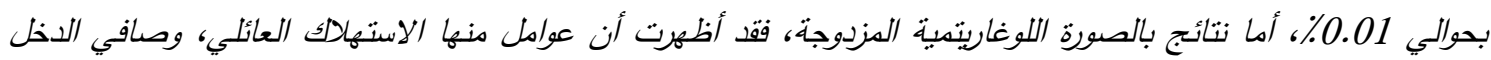

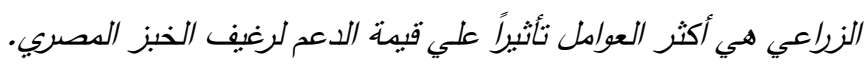

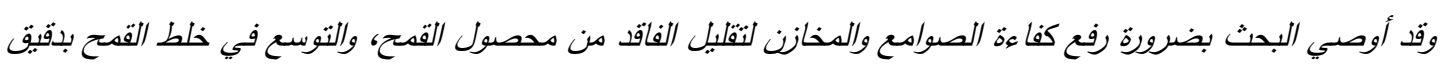
الذرة لتوفيره لكافة العواطنين، توعية المواطنين عن طريق تغنيير وترشيد عادات الاستهلاك للخبز، تثديد الرقابة علي الأجهزة

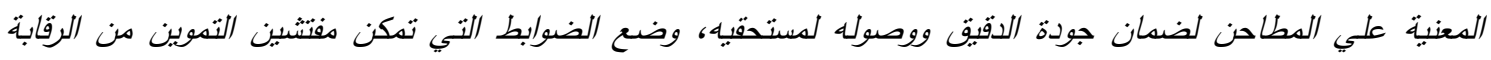

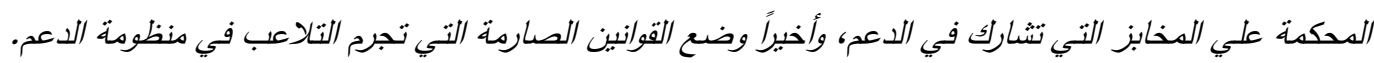
الكلمات المفتاحية: الخبز الدصرى- محصول القدح- الدعم. 


\section{A. ElSayed}

أدت إلي زيادة الفاقد الاقتصادي وعدم إمكانية تحقيق مقدمة الأهداف الإنتاجية للحد من استيراد القمح ودقيقه. وقد ساهمت سياسة دعم رغيف الخبز إلي زيادة قيمة الدعم من حوالي 1.5 مليار جنيه عام 2000، إلي حوالي 9.1 مليار جنيه عام 2015، مما ترتب عليه زيادة العبء علي الموازنة العامة للاولة وزيادة العجز في في الميزان الزراعي والذي تزايد من حوالي 4.6 مليار جنيه عام 2000 إلي حوالي 41.5 مليار جنيه عام 2014. مما جعل تلك السياسات أصبحت محل شك في تحقيق قدرتها

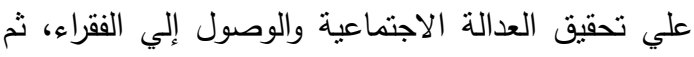

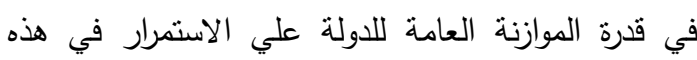
السياسة، لما تسببه من عدم كفاءة تخصيص الموارد.

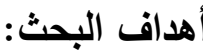

يهدف البحث بصفة عامة إلي دراسة أهم العوامل المؤثرة علي الدعم لرغيف الخبز وذلك من خلال: 1- دراسة أهم المتغيرات الاقتصادية والإنتاجية المنعلقة

$$
\text { بمحصول القمح في مصر . }
$$

2- الأهمية النسبية لدعم رغيف الخبز بالنسبة لدعم المواد الغذائية وإجمالي الدعم.

3- دراسة تطور أهم المتغيرات الاقتصادية المؤثرة علي قيمة الدعم لرغيف الخبز المصري. 4- القياس الإحصائي لأهم المتغيرات الاقتصادية المؤثرة علي قيمة الدعم لرغيف الخبز المصري.

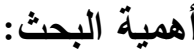

ترجع أهمية دراسة قيمة الدعم لرغيف الخبز لأهميته

الاستراتيجية، حيث يعتبر من أهم المكونات الرئيسية

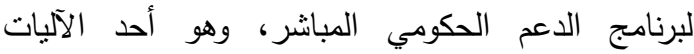

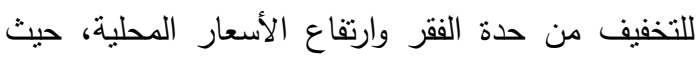

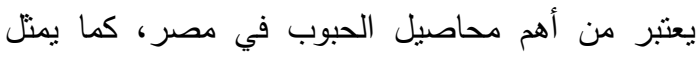
الغذاء الرئيسي في وجبات المصريين، إلا أن الزيادة المستمرة في قيمة الدعم لرغيف الخبز تؤدي إلي زيادة العبء علي الموازنة العامة للاولة نتيجة للزيادة السكانية

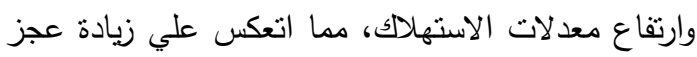

تُعد سباسة الدعم الحكومي من السياسات الأكثر شيوعاً بين الدول، مع تفاوت أهداف هذه السياسات

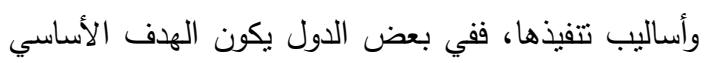

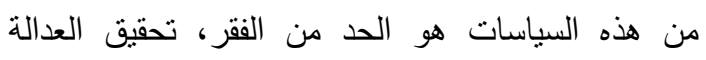

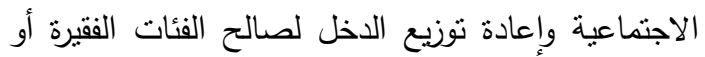
محدودي الدخل، وفي دول أخري يكون الهدف من هذه السياسة هو احتواء بعض الآثار الناجمة عن سياسات اقتصادية ومالية معينة. تعتبر قضية الدعم أحد القضايا الهامة الني تهتم بها العديد من الدول باختلاف أنظمتها السياسية والاجتماعية والاقتصادية، وتعتبر الدول النامية هي الاكثر احتباجاً لنظم الدعم من أجل مكافحة الفقر

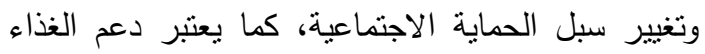
في مصر أحد المكونات الرئيسية لبرنامج الدعم الحكومي الدئي

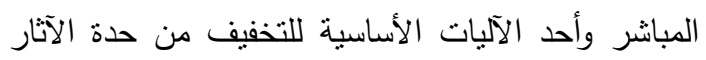

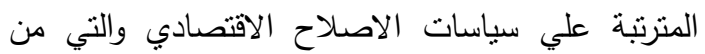

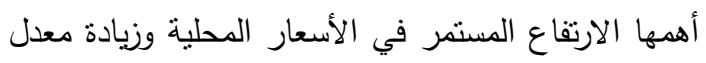

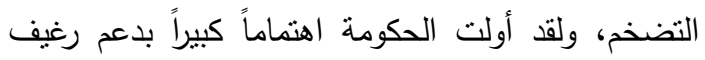

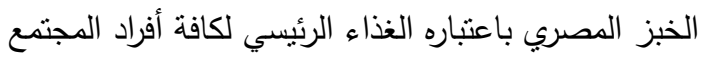

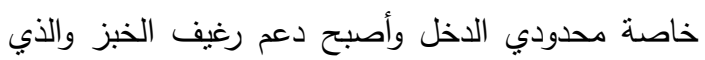

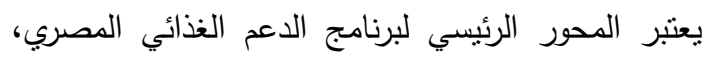

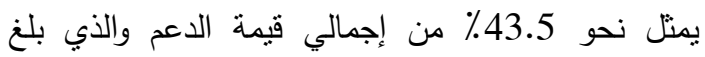
متوسطه حوالي 74.7 مليار جنيه خلال الفترة (20002015). هذا وقد اهتمت الدولة بدعم رغيف الخبز بنوعيه

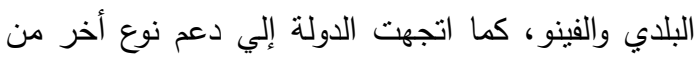
الخبز وهو الخبز البلدي الدحس. مُشكلة البحث: نواجه سياسة الدعم الموجهة لصناعة الخبز مجموعة

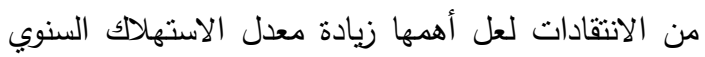
للفرد من الخبز زيادة كبيرة لا تتفق ومعدلات الاستهلاك

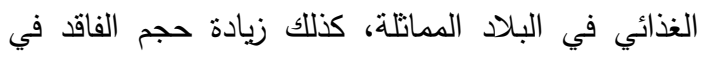

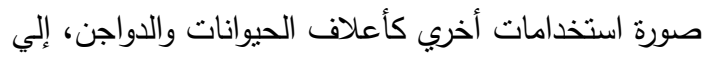
جانب زيادة معدلات الفقد النانشئ عن سوء التصنيع، كما أن الاختلالات السعرية بين القمح والمحاصيل البديلة قد 
المزروعة من محصول القمح قد بلغت حدها الأدنى حوالي 2.34 مليون فدان عام 2001، في حين بلغت حدها الأقصي حوالي 3.47 مليون فدان عام 2015، بمنتوسط عام بلغ حوالي 2.92 مليون فدان. كما نتير تقديرات المعادلة رقم (1) بالجدول رقم (2) أن المساحة المزروعة من محصول القمح نتزايد سنوياً بمقدار معنوي إحصائياً

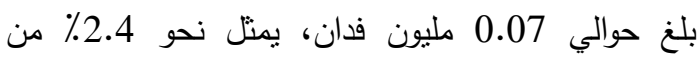

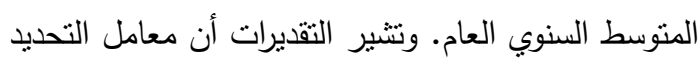
قد بلغ نحو 0.89 مما يعنى أن نحو 89 \% من من التغيرات في المساحة المزروعة تُعزي إلي عوامل أخري يعكسها

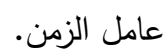

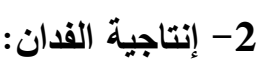

تشبير النتائج الواردة بالجدول رقم (1) بأن انتاجية

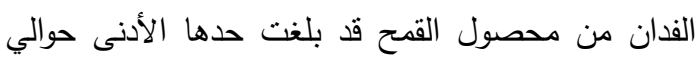
2.39 طن عام 2010، في حين بلغت حدها الأقصي حوالي 2.80 طن عام 2013، بمتوسط عام بلغ حوالي 2.71 طن. كما نتير تقديرات المعادلة رقم (2) أن انتاجية الفدان من محصول القمح تنزايد سنوياً بمقدار غير معنوي إحصائياً بلغ حوالي 0.003 طن.

$$
\text { 3- الإنتاج المحلي: }
$$

تنثير النتائج بأن الإنتاج الكلي من محصول القمح قد

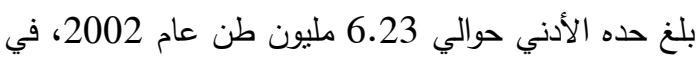

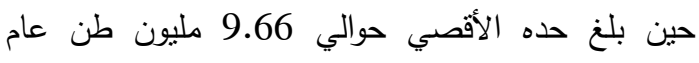
2015، بمتوسط عام بلغ حوالي 7.89 مليون طن.

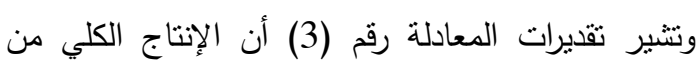

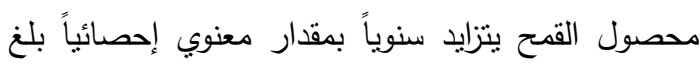

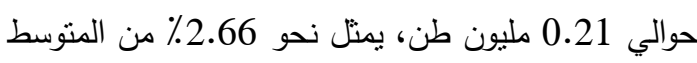

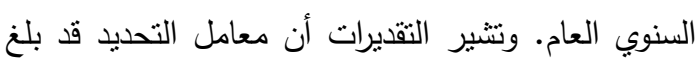

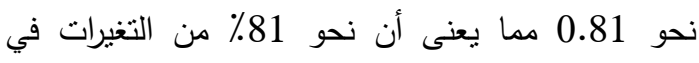
الإنتاج الكلي تُعزي إلي عوامل أخري يعكسها عامل

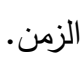

الميزان الزراعي، وهو ما بعطي أهمية لدراسة أهم العوامل

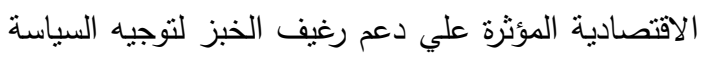

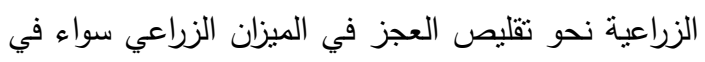

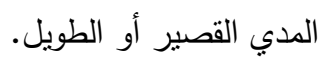
الطريقة البحثية: لتحقيق الأهداف سالفة الذكر، فقد اعتددت الدراسة على أسلوبي التحليل الاقتصادي الوصفي والتحليل

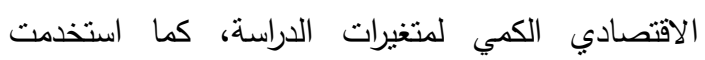
الدراسة العديد من أساليب التحليل الإحصائي وأدواته منل لإنل

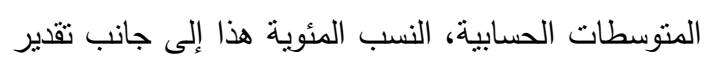

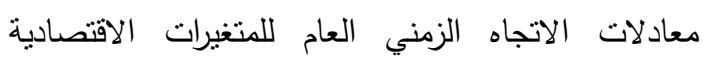

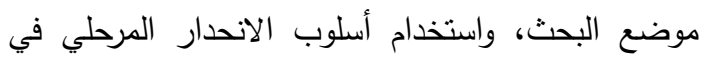

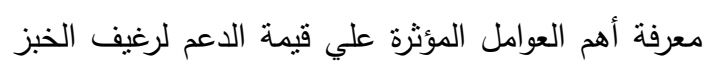
المصري. مصادر جمع البيانات: اعتمدت الدراسة في تحقيق أهدافها على البيانات الثانوية المكتية والنشرات الخاصة والصادرة عن الجهاز المركزي للتعبئة العامة والإحصاء، وكذللك النشرات التي التئي

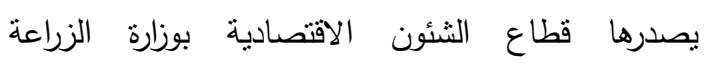
واسنصلاح الأراضي، بالإضافة إلي البحوث والدراسات العلمية المتعلقة بموضوع البحث. مناقشة وعرض النتائج أولاً: توصيف المتغيرات الرئيسية المرتبطة بمحصول القمح في مصر:

يتناول هذا الجزء توصيف المتغيرات الإنتاجية

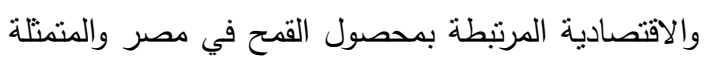
في المساحة المزروعة، الإنتاجية الفدانية، الإنتاج الكلي

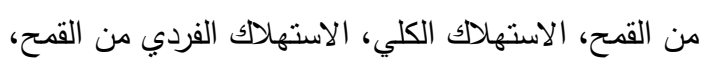

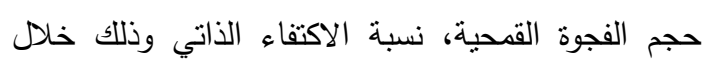
الفترة (2000-2015).

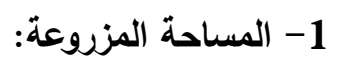
تتشير النتائج الواردة بالجدول رقم (1) بأن المساحة 


\section{5- الاستهلاك المحلي:}

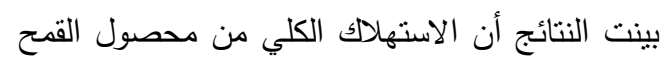

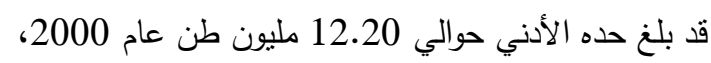
في حين بلغ حده الأقصي حوالي 18.65 مليون طن عام الإني 2012، بمتوسط عام بلغ حوالي 14.98 مليون طن.

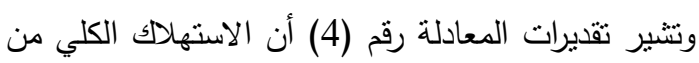

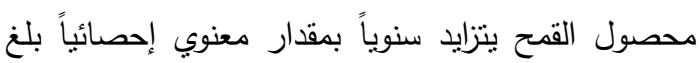

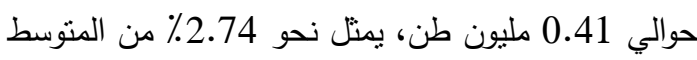

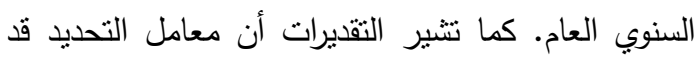

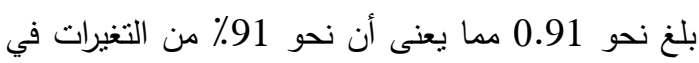

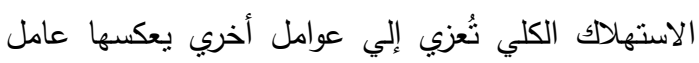

4- الاستهلاك الفردي من القمح:

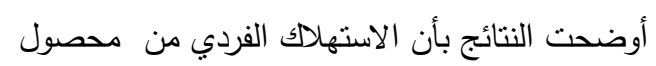
القمح قد بلغ حده الأدنى حوالي 186.01 كجم عام الأم 2003، في حين بلغ حده الأقصي حوالي 225.92 كجم حلم الادي

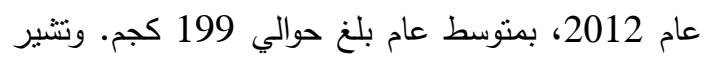
تقديرات المعادلة رقم (7) أن الاستهلاك الفردي من القمح يتزايد سنوياً بمقدار معنوي إحصائياً بلغ حوالي 1.32

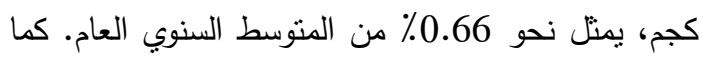

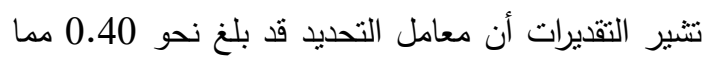

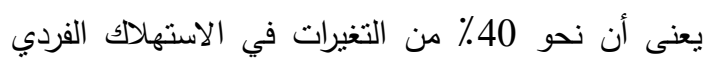

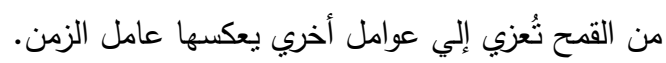
الزمن.

جدول رقم (1): المتغيرات المرتبطة بمحصول القمح في مصر خلال الفترة (2000-2015)

\begin{tabular}{|c|c|c|c|c|c|c|c|}
\hline \begin{tabular}{|c|} 
نسبة الاكتفاء \\
(الاتي \\
$(\%)$
\end{tabular} & (القمحية & (الاستهلاك & $\begin{array}{c}\text { الاستهلاك } \\
\text { الفردي } \\
\text { (كجم) }\end{array}$ & $\begin{array}{c}\text { (الإنتاج } \\
\text { (مليون طن) } \\
\text { الكلي }\end{array}$ & إنتاجية & 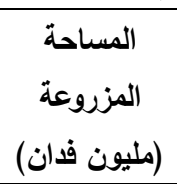 & السنة \\
\hline 53.77 & 5.64 & 12.20 & 190.92 & 6.56 & 2.67 & 2.46 & 2000 \\
\hline 49.17 & 6.46 & 12.71 & 194.94 & 6.25 & 2.67 & 2.34 & 2001 \\
\hline 49.84 & 6.27 & 12.50 & 187.97 & 6.23 & 2.70 & 2.45 & 2002 \\
\hline 54.79 & 5.71 & 12.63 & 186.01 & 6.92 & 2.73 & 2.5 & 2003 \\
\hline 55.40 & 5.78 & 12.96 & 187.01 & 7.18 & 2.76 & 2.61 & 2004 \\
\hline 58.86 & 5.86 & 13.83 & 195.62 & 8.14 & 2.73 & 2.99 & 2005 \\
\hline 56.72 & 6.31 & 14.58 & 201.04 & 8.27 & 2.70 & 3.06 & 2006 \\
\hline 49.63 & 7.49 & 14.87 & 202.04 & 7.38 & 2.72 & 2.72 & 2007 \\
\hline 53.59 & 6.91 & 14.89 & 198.00 & 7.98 & 2.73 & 2.92 & 2008 \\
\hline 55.11 & 6.94 & 15.46 & 201.04 & 8.52 & 2.71 & 3.15 & 2009 \\
\hline 45.21 & 8.69 & 15.86 & 201.52 & 7.17 & 2.39 & 3.07 & 2010 \\
\hline 48.80 & 8.78 & 17.15 & 212.96 & 8.37 & 2.74 & 3.06 & 2011 \\
\hline 47.13 & 9.86 & 18.65 & 225.92 & 8.79 & 2.78 & 3.16 & 2012 \\
\hline 56.7 & 7.22 & 16.50 & 197.20 & 9.46 & 2.80 & 3.38 & 2013 \\
\hline 52.10 & 8.55 & 17.10 & 199.34 & 9.28 & 2.74 & 3.39 & 2014 \\
\hline 54.30 & 8.14 & 17.80 & 202.36 & 9.66 & 2.78 & 3.47 & 2015 \\
\hline 52.57 & 7.16 & 14.98 & 199.0 & 7.89 & 2.71 & 2.92 & لمتوسط \\
\hline
\end{tabular}

المصدر: الجهاز المركزي للنعبئة العامة والإحصاء، الكتاب الإحصائي السنوي، نشرات المساحة المحصولية للإنتاج النباتي،أعداد متفرقة. 
جدول رقم (2): الاتجاه الزمني العام لأهم المتغيرات الاقتصادية المرتبطة بمحصول القمح في مصر خلال الفترة (2000-

(2015

\begin{tabular}{|c|c|c|c|c|c|}
\hline$F$ & $\mathrm{R}^{2}$ & $\begin{array}{c}\text { معدل النمو } \\
\text { \% }\end{array}$ & المعادلة & المتغير & المعادلة \\
\hline $107.99 * *$ & 0.89 & 2.40 & $\begin{array}{l}\widehat{\mathrm{Y}}_{\mathrm{t}}=2.31+0.07 \mathrm{t} \\
\quad(34.43)^{* *}(10.39)^{* *}\end{array}$ & 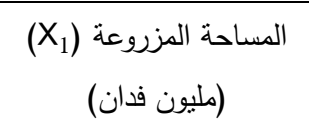 & 1 \\
\hline 0.44 & 0.03 & 0.11 & $\begin{array}{r}\widehat{Y}_{t}=2.68+0.003 t \\
(54.02)^{* * *}(0.66)\end{array}$ & $\begin{array}{l}\text { الإنتاجية (طن/2) } \\
\text { (طدان) }\end{array}$ & 2 \\
\hline $59.09 * *$ & 0.81 & 2.66 & $\begin{aligned} \widehat{Y}_{\mathrm{t}}=6.09+0.21 \mathrm{t} \\
(23.03)^{* * *}(7.69)^{* * *}\end{aligned}$ & 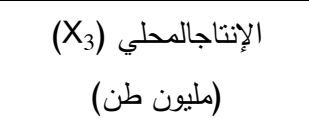 & 3 \\
\hline $9.24 * *$ & 0.40 & 0.66 & $\begin{aligned} \widehat{Y}_{t}= & 187.79+1.32 t \\
& (44.78)^{* * *}(3.04)^{* * *}\end{aligned}$ & $\begin{array}{l}\text { الاستهلاك الفردي (كم) } \\
\text { (كج) }\end{array}$ & 4 \\
\hline 139.18 ** & 0.91 & 2.74 & $\begin{aligned} \widehat{Y}_{\mathrm{t}} & =11.46+0.41 \mathrm{t} \\
& (33.80)^{* *}(11.80)^{* * *}\end{aligned}$ & $\begin{array}{c}\text { الاستهلاك المحلي (X) } \\
\text { (مليون طن) }\end{array}$ & 5 \\
\hline $25.16 * *$ & 0.64 & 3.07 & $\begin{aligned} \widehat{Y}_{t}= & 5.30+0.22 t \\
& (12.56)^{* *}(5.02)^{* * *}\end{aligned}$ & حجم الفجوة (Y) حليون طن) & 6 \\
\hline 0.18 & 0.01 & 0.17 & $\begin{array}{l}\widehat{Y}_{t}=53.35-0.09 t \\
(25.56)^{* *}(-0.43)^{* * *}\end{array}$ & 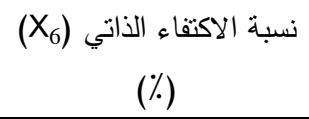 & 7 \\
\hline
\end{tabular}

حيث:

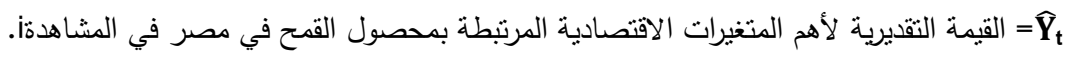

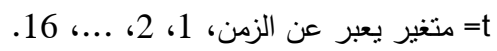
المصدر: نتائج الحاسب الآلي للبيانات الواردة بالجدول رقم (1) بالبحث.

7 - تسبة الاكتفاء الاتي:

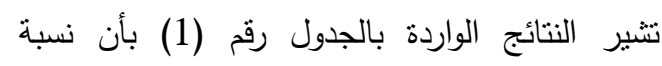
الاكتفاء الذاتي من محصول القمح قد بلغت حدها الأدني نحو 47.13 \%جنيه عام 2012، في حين بلغت حدها

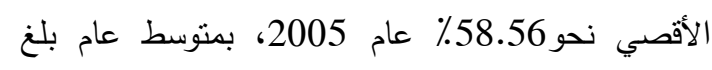

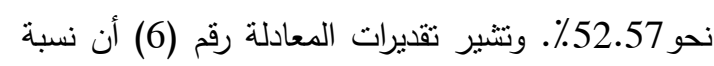
الاكتفاء الذاتي تتتاقص سنوياً بمقدار غير معنوي إحصائياً بلغ حوالي 0.09٪.

ثانياً: تطور قيمة الدعم الموجه للسلع الغذائية ورغيف الخبز وإجمالي الدعم:

\section{6- حجم الفجوة القمية:} أكدت النتائج الواردة بالجدول رقم (1) أن حجم الفمدة الفجوة

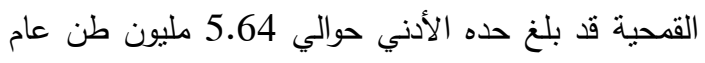
2000، في حين بلغ حده الأقصي حوالي 9.86 مليون

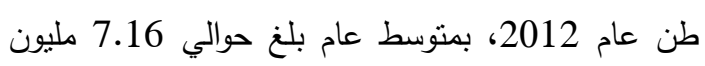
طن. وتشير تقديرات المعادلة رقم (5) أن حجم الفجوة

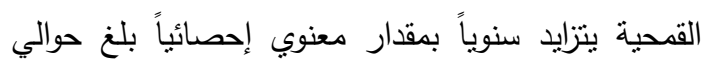

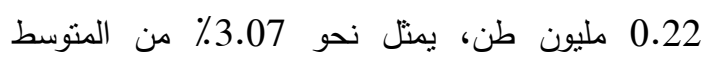

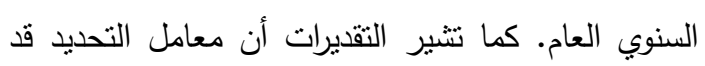

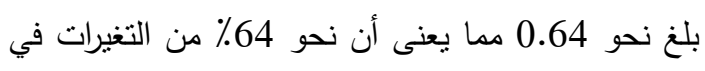

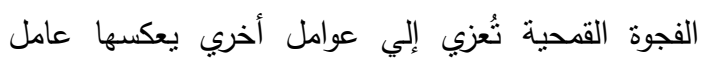

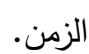


الدعم. وتتثبر تقديرات المعادلة رقم (8) بالجدول رقم (4) أن قيمة الدعم لرغيف الخبز يتزايد سنوياً بمقدار معنوي إحصائياً بلغ حوالي 0.80 مليار جنيه، يمثل نحو لو ب.35٪

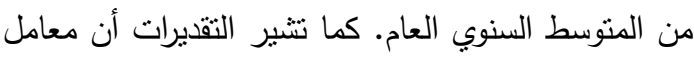

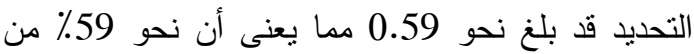
التغيرات في دعم رغيف الخبز تُعزي إلي عوامل أخري

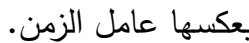

1 - الاعم الموجه لرغيف الخبز:

تثير النتائج الواردة بالجدول رقم (3) بأن قيمة الدعم الموجه لرغيف الخبز قد بلغ حده الأدني حوالي 1.5 مليار

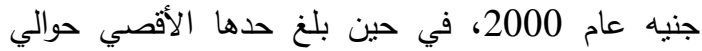
16.5مليار جنيه عام 2009، بمتوسط عام بلغ حوالي 8.6 مليار جنيه. كما بلغ المتوسط العام لقيمة الدعم الموجه لرغيف الخبز بالنسبة للاعم الموجة للمواد الغذائية نحو 71.4٪، مقابل نحو 43.5\% بالنسبة لإجمالي قيمة

جدول رقم (3): تطور قيمة دعم رغيف الخبز بالنسبة لدعم المواد الغذائية واجمالي الاعم خلال الفترة (2000-2015)

\begin{tabular}{|c|c|c|c|c|c|c|}
\hline نصيب الفرد & \% لاعم الرغيف من & ٪ دعم المواد الغذائية & إجمالي الدعم & دلغائية & لرغيف الخبز & السنة \\
\hline 78.25 & 38.33 & 63.89 & 5.0 & 2.7 & 1.5 & 2000 \\
\hline 75.15 & 43.48 & 71.43 & 4.9 & 3.1 & 1.9 & 2001 \\
\hline 90.23 & 55.77 & 78.38 & 6.0 & 3.6 & 2.3 & 2002 \\
\hline 101.62 & 45.65 & 56.25 & 6.9 & 4.2 & 3.0 & 2003 \\
\hline 150.07 & 11.44 & 65.96 & 10.4 & 7.4 & 5.8 & 2004 \\
\hline 195.19 & 14.81 & 85.11 & 13.8 & 11.2 & 6.3 & 2005 \\
\hline 750.69 & 18.05 & 92.68 & 54.2 & 9.4 & 6.2 & 2006 \\
\hline 733.70 & 17.59 & 78.20 & 54.0 & 9.4 & 8.0 & 2007 \\
\hline 1119.68 & 13.14 & 73.21 & 84.2 & 16.4 & 15.2 & 2008 \\
\hline 1219.77 & 13.67 & 46.48 & 93.8 & 21.1 & 16.5 & 2009 \\
\hline 1189.33 & 8.20 & 35.64 & 93.6 & 16.8 & 12.3 & 2010 \\
\hline 1380.85 & 6.59 & 33.74 & 111.2 & 32.7 & 15.2 & 2011 \\
\hline 1595.40 & 6.43 & 33.24 & 131.7 & 30.3 & 10.8 & 2012 \\
\hline 1993.55 & 5.20 & 28.80 & 166.8 & 32.6 & 11.0 & 2013 \\
\hline 2138.03 & 11.46 & 51.08 & 183.4 & 35.5 & 11.8 & 2014 \\
\hline 1990.68 & 38.33 & 63.89 & 175.1 & 31.6 & 9.1 & 2015 \\
\hline 995.34 & 43.48 & 71.43 & 74.69 & 16.75 & 8.56 & المنوسط \\
\hline
\end{tabular}

المصدر: جمهورية مصر العربية، وزارة المالية، بيانات الحساب الختامي للموازنة العامة للدولة، أعداد متفرقةwww.mof.gov.eg. 
جدول رقم (4): الاتجاه الزمني العام لقيمة الدعم الموجه للسلع الغذائية ورغيف الخبز والإجمالي العام للاعم خلال الفترة

(2015-2000)

\begin{tabular}{|c|c|c|c|c|}
\hline $\mathrm{F}$ & $\mathrm{R}^{2}$ & المعادلة & المتغير & رقم المعادلة \\
\hline $19.74 * *$ & 0.59 & $\begin{aligned} \widehat{\mathrm{Y}}_{\mathrm{t}}= & 1.78+0.80 \mathrm{t} \\
(1.02) & (4.44)^{* * *}\end{aligned}$ & $\begin{array}{l}\text { دعم رغيف الخبز (Y) } \\
\text { (مليار جنبه) }\end{array}$ & 8 \\
\hline $137.78 * *$ & 0.91 & $\begin{aligned} \widehat{\mathrm{Y}}_{\mathrm{t}}=-3.95+2.44 \mathrm{t} \\
\quad(-1.97)(11.74)^{* * *}\end{aligned}$ & $\begin{array}{c}\text { دعم المواد الغذائية } \\
\text { (مليار جنيه) }\end{array}$ & 9 \\
\hline $225.12^{* * *}$ & 0.94 & $\begin{array}{c}\widehat{Y}_{t}=-38.03+13.26 t \\
\quad(-4.45)^{* *}(15.03)^{* *}\end{array}$ & إجمالي الدعم & 10 \\
\hline $243.96 \% *$ & 0.95 & $\begin{array}{r}\widehat{Y}_{t}=-390.66+154.80 t \\
(-4.08)^{* * *}(15.62)^{* * *}\end{array}$ & $\begin{array}{c}\text { نصيب الفرد من الدعم } \\
\text { (جنيه) }\end{array}$ & 11 \\
\hline
\end{tabular}

حيث:

T: القيمة التقديرية لقيمة دعم رغيف الخبز ودعم المواد الغذائية وإجمالي الدعم ومنوسط نصيب الفرد من الدعم المشاهدةأ.

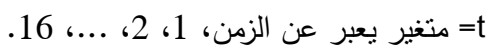

المصدر: نتائج الحاسب الآلي للبيانات الواردة بالجدول رقم (3) بالبحث.

17.8 من المتوسط السنوي العام. كما تشير التقديرات

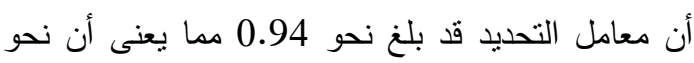

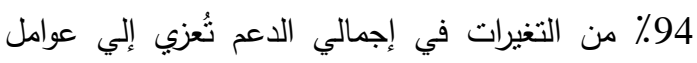

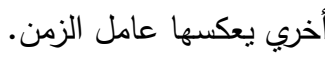

4- تطور نصيب الفرد من الدعم: أوضحت النتائج أن نصيب الفرد من الدعم قد بلغ حده الأدنى حوالي 75.2 جنيه عام 2001، ألهاب في حين بلغ حده الأقصي حوالي 2138 جنيه عام 2014، بمنوسط عام بلغ حوالي 995.3 جنيه. وتتشير تقديرات المعادلة رقم (11) بالجدول رقم (4) أن نصيب الفرد من الدعم يتزايد

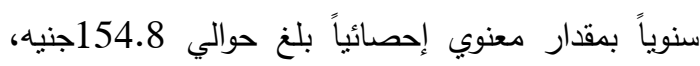

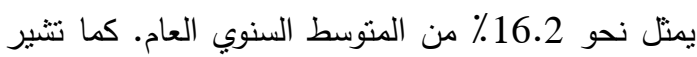

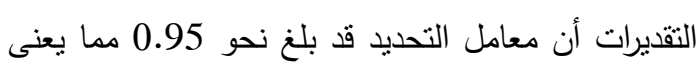
أن نحو 95\% من التغيرات في نصيب الفرد من الدعم تُعزي إلي عوامل أخري بعكسها عامل الزمن.

ثالثاً: أهم المتغيرات الاقتصادية المؤئرة علي قيمة دعم رغيف الخبز المصري: يستعرض هذا الجزء أهم المتغيرات الاقتصادية المؤثرة علي قيمة دعم رغيف الخبز المصري (Y) والمتنلة في:
2- الدعم الموجه للسلع الغذائية: أوضحت النتائج أن قيمة الدعم الموجه للمواد الغذائية الفئة

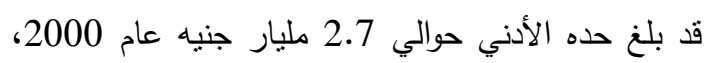

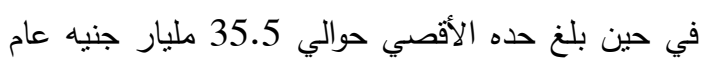
2014، بمتوسط عام بلغ حوالي 16.8 مليار جنيه. وتثبر تقديرات المعادلة رقم (9) أن قيمة الدعم الموجه

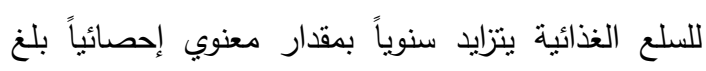

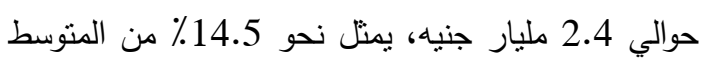

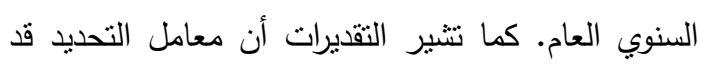

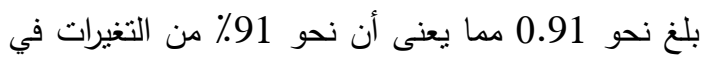
دعم المواد الغذائية تُعزي إلي عوامل أخري يعكسها عامل

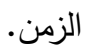
3- 3 تطور إجمالي الدعم: أنشارت النتائج أن قيمة إجمالي الدعم: الدعم قد بلغ حده

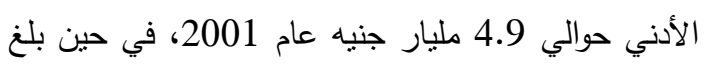
حده الأقصي حوالي 183.4 مليار جنيه عام 2014، بمتوسط عام بلغ حوالي 74.7 مليار جنيه. وتنشير تقديرات المعادلة رقم (10) أن إجمالي الدعم يتزايد سنوياً بمقدار

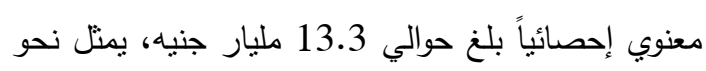




\section{A. ElSayed}

بلغ نحو 0.74 مما يعنى أن نحو 74٪ من التغيرات في قيمة الصادرات الزراعية تُعزي إلي عوامل أخري بعكسها

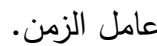

\section{4- قيمة الواردات القمحية:(X)}

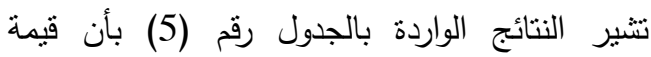
الواردات القحية قد بلغت حدها الأدني حوالي 1.7 مليار جنيه عام 2001، في حين بلغت حدها الأقصي حوالي لئي 36.7 مليار جنيه عام 2013، بمتوسط عام بلغ حوالي 11.3 مليار جنيه. وتشير تقديرات المعادلة رقم (15) أن أن قيمة الواردات القحية تنزايد سنوياً بمقدار معنوي إحصائياً

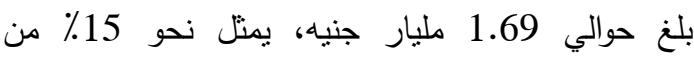

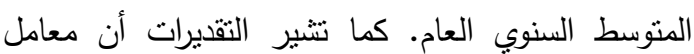

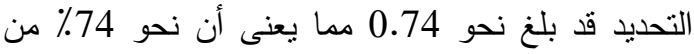

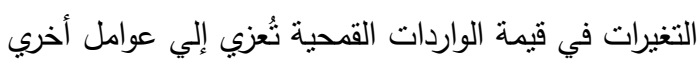

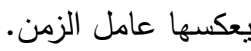

\section{5-}

تنثير الننائج الواردة بالجدول رقم (5) أن عجز الميزان

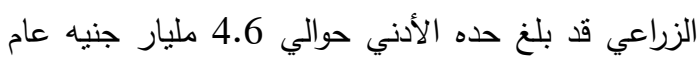
2000، في حين بلغ حده الأقصي حوالي 41.5 مليار جنيه عام 2014، بمتوسط عام بلغ حوالي 14.6 مليار

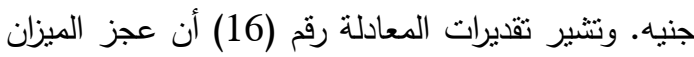

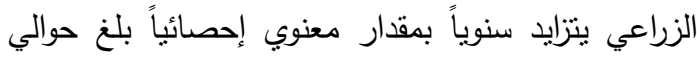

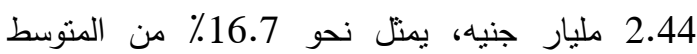
السنوي العام. كما تثير التقديرات أن معامل التحديد قد بد

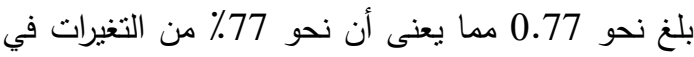
عجز الهيزان الزراعي تُعزي إلي عوامل أخري بعكسها

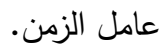

\section{6- سعر استيراد القمح:(X)}

تثتير النتائج الواردة بالجدول رقم (5) بأن سعر استيراد

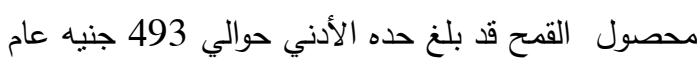
2000، في حين بلغ حده الأقصي حوالي 5398 جنيه عام 2013، بمتوسط عام بلغ حوالي 1760.4 جنيه. وتثير تقديرات المعادلة رقم (17) أن سعر استيراد القمح

$$
\text { 1 }
$$

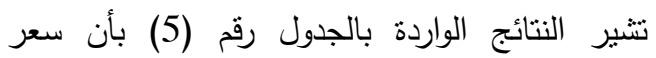
الصرف قد بلغ حده الأدني حوالي 3.65 جنيه/:دولار عام 2000، في حين بلغ حده الأقصي حوالي 7.60 دولار/جنيه عام 2015، بمتوسط عام بلغ حوالي 5.7

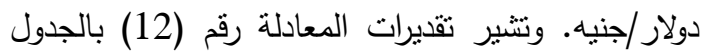
رقم (6) أن سعر الصرف بيزايد سنوياً بمقدار معنوي

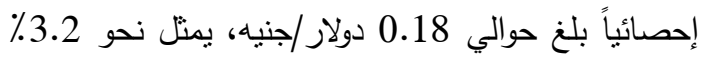
من الدتوسط السنوي العام. كما تشير النقبيرات أن معامل

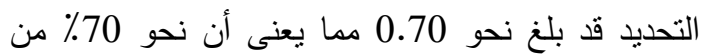
التغيرات في سعر الصرف ثُرزي إلي عوامل أخري بعكسها

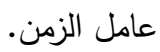

\section{2-}

تثير النتائج الواردة بالجدول رقم (5) بأن صافي الافي الدخل الزراعي قد بلغ حده الأدني حوالي 50.7 مليار

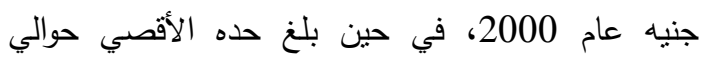

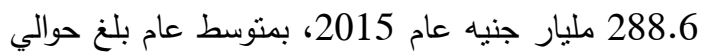

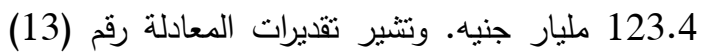
أن صافي الاخل الزراعي يتزايد سنوياً بمقدار معنوي

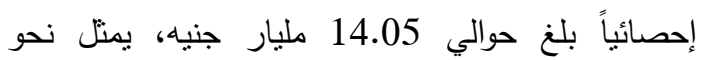
11.4٪ من الدوسط السنوي العام. كما تثتير التقليرات

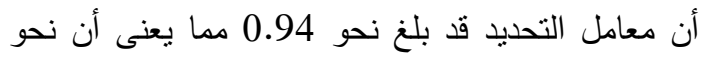

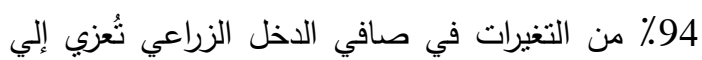
عوامل أخري بعكسها عامل الزمن.

\section{3- قيمة الصادرات الزراعية:X}

تشير الننائج الواردة بالجدول رقم (5) بأن قيمة الصادرات الزراعية قد بلغت حدها الأدني حوالي 1.8 مليار جنيه عام 2000، في حين بلغت حدها الأقصي

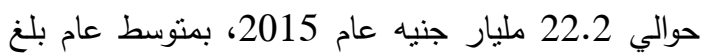

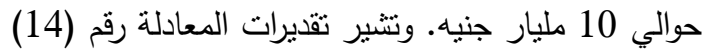
أن قيمة الصادرات تنزايد سنوياً بمقدار معنوي إحصائياً بلغ

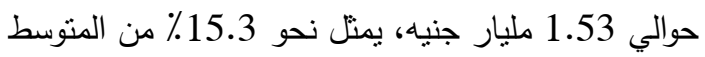
السنوي العام. كما تثثير النقيرات أن معامل النحديد قد الد 


\begin{tabular}{|c|c|c|c|c|c|c|c|c|c|c|c|c|c|c|c|c|c|}
\hline 2 & 요 & 용 & 엉 & ণ্ণি & 몽 & '용 & 유 & ్ㅗ & 옹 & 용 & 음 & 콩 & 월 & 을 & 焗 & 응 & $\begin{array}{l}\overline{7} \\
3 \\
3\end{array}$ \\
\hline 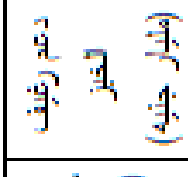 & $\because$ & $\stackrel{9}{\longrightarrow}$ & व & 우 & مَ & $\begin{array}{l}9 \\
\emptyset\end{array}$ & वै & 임 & ฯุ & $\mid$\begin{tabular}{l} 
? \\
\hdashline \\
\hdashline
\end{tabular} & $\stackrel{9}{9}$ & ำ & 吕 & 울 & $\stackrel{\infty}{\leftrightarrows}$ & $\vec{a}$ & 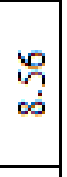 \\
\hline $\mathrm{g}^{3}$ & $\left|\begin{array}{l}1 \\
0 \\
0 \\
c\end{array}\right|$ & ठ․ & $\begin{array}{l}\text { @ొ } \\
\dot{y}\end{array}$ & 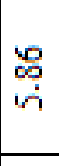 & $\frac{9}{a}$ & 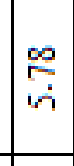 & $\stackrel{m}{r}$ & 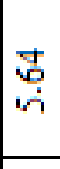 & そे & 点 & ช⿱ & ๙ู & b & $\mid \begin{array}{l}\infty \\
\dot{0} \\
\dot{0}\end{array}$ & 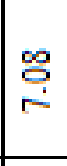 & $\mid \stackrel{8}{\circ}$ & ๆ \\
\hline 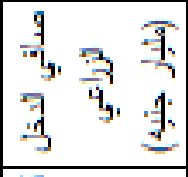 & ํํㄹ & | & ? & $\begin{array}{l}n \\
\infty \\
\infty\end{array}$ & ? & $\begin{array}{l}9 \\
\check{n} \\
\alpha\end{array}$ & 辛 & 9ே & 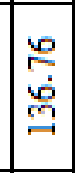 & 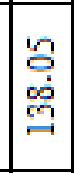 & 突 & 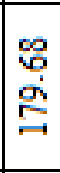 & 웜 & $\begin{array}{l}\infty \\
\text { mà } \\
\text { m. }\end{array}$ & r. & \begin{tabular}{l}
$n$ \\
2 \\
$\infty$ \\
$\infty$ \\
\hdashline \\
\hdashline \\
0
\end{tabular} & 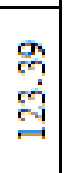 \\
\hline 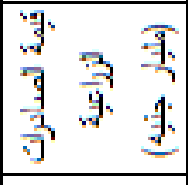 & 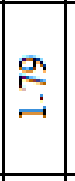 & 品 & 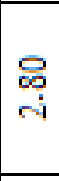 & $\begin{array}{l}\text { 음 } \\
\text { 和 }\end{array}$ & 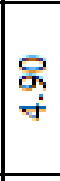 & 突 & 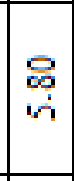 & 오 & g̀ & @ે & 先 & $\vec{a}$ & 검 & $\begin{array}{l}\infty \\
\stackrel{a}{a}\end{array}$ & ồ & 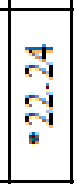 & $\begin{array}{l}\text { 엉 } \\
0 \\
0\end{array}$ \\
\hline 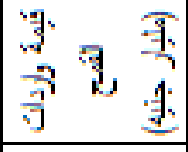 & 걱 & 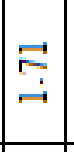 & $\overrightarrow{0}$ & ప్ & $\stackrel{9}{\stackrel{9}{+}}$ & 유 & 㝵 & 式 & $\stackrel{\vec{n}}{\Xi}$ & 옥 & 옹 & 总 & 管 & $\mid \begin{array}{l}1 \\
0 \\
\dot{0} \\
\dot{0} \\
\end{array}$ & \begin{tabular}{|l|}
1 \\
$\infty$ \\
$d$ \\
$d$
\end{tabular} & 움 & $\begin{array}{l}\stackrel{9}{9} \\
\stackrel{2}{\rightrightarrows}\end{array}$ \\
\hline 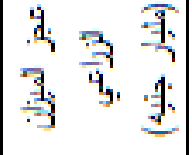 & $\begin{array}{l} \\
0 \\
\dot{q}\end{array}$ & में & o & 吕 & $\stackrel{9}{\dot{\gamma}}$ & $\begin{array}{l}9 \\
\infty\end{array}$ & $\vec{r}$ & 궁 & '2 & $\stackrel{\text { a }}{\Im}$ & '응 & ๙า & 嶉 & י & ? & \begin{tabular}{l} 
省 \\
品 \\
\hdashline
\end{tabular} & $\begin{array}{l}\stackrel{\infty}{7} \\
\dot{\Xi} \\
\end{array}$ \\
\hline 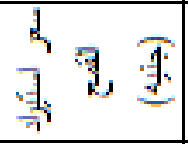 & ga & 号 & 吉 & \% & ํㅗㅇ & 劣 & 䓌 & 骂 & 怘 & 坖 & नूন & 量 & 居 & $\begin{array}{l}\infty \\
\text { 品 } \\
\text { in }\end{array}$ & $\begin{array}{l}\infty \\
0 \\
0 \\
\infty\end{array}$ & 要 & 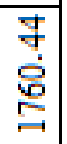 \\
\hline 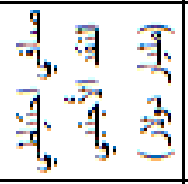 & 襟 & 吾 & 鹪 & $\begin{array}{l}\vec{D} \\
\dot{0} \\
\dot{\square}\end{array}$ & 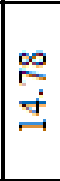 & প్ & \begin{tabular}{l}
9 \\
$\stackrel{2}{ }$ \\
\cline { 1 - 1 }
\end{tabular} & \begin{tabular}{l}
$\mathscr{0}$ \\
\hdashline \\
$\infty$
\end{tabular} & 点 & $\stackrel{m}{\stackrel{m}{\vec{g}}}$ & ปี & 号 & 癷 & 总 & 它 & 겸 & $\begin{array}{l}0 \\
\stackrel{2}{二} \\
\end{array}$ \\
\hline 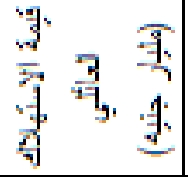 & ğ & $\exists$ & ન્વિ & 号 & 움 & 売 & 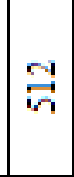 & 离 & 哭 & $\vec{亏}$ & 咨 & $\stackrel{\varrho}{\varrho}$ & 콩 & 鸽 & $\vec{g}$ & $\mid \begin{array}{l}\infty \\
\infty \\
\text { âd }\end{array}$ & 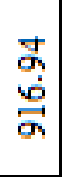 \\
\hline 年青心 & $\begin{array}{l}\infty \\
\sim \\
\sim\end{array}$ & $\ddot{\sim}$ & 궁 & $\stackrel{ }{\varrho}$ & 움 & 움 & $\stackrel{ }{\mathrm{G}}$ & $\ddot{0}$ & 웅 & m & a & 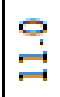 & $\dddot{m}$ & $\begin{array}{l}\infty \\
\alpha \\
\alpha\end{array}$ & ç一 & $\stackrel{\text { 品 }}{\leftrightarrows}$ & $\begin{array}{l}\infty \\
\vdots \\
\infty\end{array}$ \\
\hline 52 & $\cong$ & 웍 & $\exists$ & 음 & 음 & 음 & a & ar & 음 & a & 突 & 㝵 & 음 & 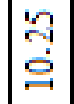 & $\stackrel{n}{\sim}$ & वे & $\begin{array}{l}\circ \\
\infty \\
\sigma\end{array}$ \\
\hline $\begin{array}{l}9.9 \\
3 \\
3 \\
3\end{array}$ & $\begin{array}{l}\text { 오 } \\
\text { ஸ่ }\end{array}$ & 옹 & 号 & 옴 & ભำ & 六 & 오 & m & مิ & 量 & 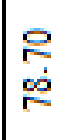 & กั & $\begin{array}{l}2 \\
\text { 今े } \\
\text { c }\end{array}$ & $\mid \begin{array}{c}\mathbf{b} \\
\stackrel{1}{\infty} \\
\infty\end{array}$ & \begin{tabular}{l}
$\infty$ \\
\multirow{2}{\prime}{} \\
$\infty$ \\
$\infty$
\end{tabular} & $\begin{array}{l}\stackrel{8}{2} \\
\tilde{5} \\
\infty\end{array}$ & 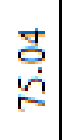 \\
\hline
\end{tabular}


معدل التضخم تُعزي إلي عوامل أخري يعكسها عامل

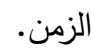

\section{0 - سعر الخصم:(X)}

تثتير النتائج الواردة بالجدول رقم (5) بأن سعر

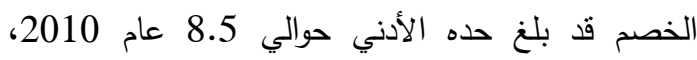
2011، في حين بلغ حده الأقصي حوالي 12 عام عال عام عامي 2000، 2001، بمتوسط عام بلغ حوالي 9.8. وبتثير تقديرات المعادلة رقم (21) أن سعر الخصم يتناقص سنوياً

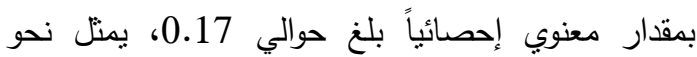

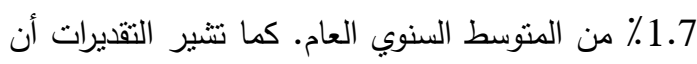

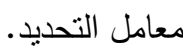

$$
\text { 11 }
$$

تثتير النتائج الواردة بالجدول رقم (5) بأن عدد السكان

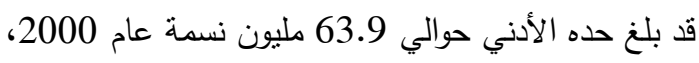
في حين بلغ حده الأقصي حوالي 87.9 مليون نسمة عام الامن 2015، بمتوسط عام بلغ حوالي 75 مليون نسمة. وتثنير تقديرات المعادلة رقم (22) أن عدد السكان يتزايد سنوياً

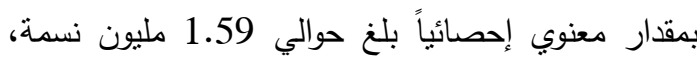
يمنل نحو 2.1٪ من المنوسط السنوي العام. كما تنشير

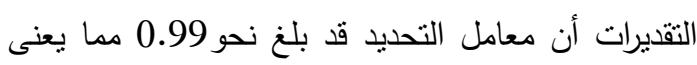
أن نحو 99٪ من التغيرات في قيمة الواردات القحية تُعزي إلي عوامل أخري يعكسها عامل الزمن.

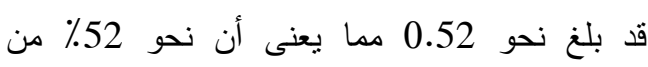
التغيرات في سعر الخصم تُعزي إلي عوامل أخري يعكسها

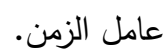

رابعاً: القياس الإحصائي لأهم المتغيرات الاقتصادية المؤثرة علي قيمة الاعم

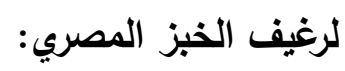

1- - 1 - 1الصورة الخطية:

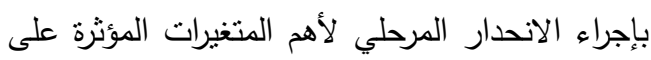

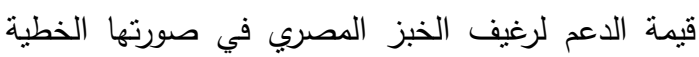
والموضحة بالمعادلة رقم (23) بالجدول رقم (7)، أظهرت
ينزايد سنوياً بمقدار معنوي إحصائياً بلخ حوالي 193.22

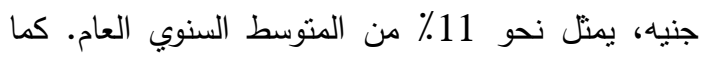
تثشير التقديرات أن معامل التحديد قد بلغ نحو 0.55 من ما يعنى أن نحو 55٪ من التغيرات في سعر استيراد القمح تُعزي إلي عوامل أخري يعكسها عامل الزمن.

\section{7- صافي احتياطي النقد الأجنبي:(X)}

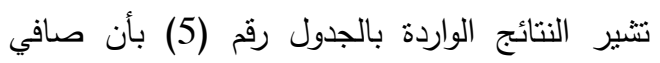
احتياطي النقد الأجنبي قد بلغ حده الأدني حوالي 14.2

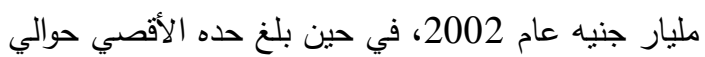
35.2 مليار جنيه عام 2010، بمنوسط فئ عام بلغ حوالي 21.2 ملبار جنيه. وتشير تقديرات المعادلة رقم (18) أن صافي احتياطي النقد الأجنبي يتزايد سنوياً بمقدار غير لئر معنوي إحصائياً بلغ حوالي 0.46 مليار جنيه.

\section{8- قيمة الاستهلاك العائلي:(X8)}

تشير النتائج الواردة بالجدول رقم (5) بأن قيمة الاستهلاك العائلي قد بلغت حدها الأدني حوالي 296 مليار جنيه عام 2000، في حين بلغت حدها الأقصي حوالي 2286 مليار جنيه عام 2015، بمار فئ حنوسط عام بلغ حوالي 916.9 مليار جنيه. وتثشير تقديرات المعادلة رقم (19) أن قيمة الاستهلاك العائلي نتزايد سنوياً بمقدار

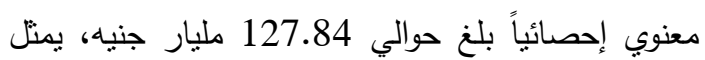
نحو 14\% من المنوسط السنوي. كما تثير التقديرات أن

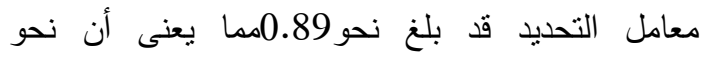

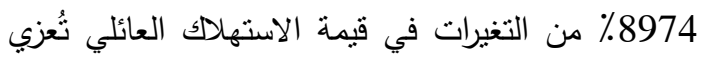
إلي عوامل أخري يعكسها عامل الزمن.

\section{9- 9 - 9}

تشير النتائج الواردة بالجدول رقم (5) بأن معدل

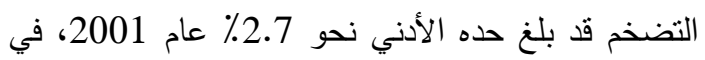

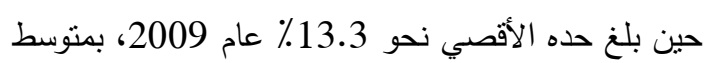
عام بلغ نحو 9\% وتثير تقديرات المعادلة رقم (20) أن

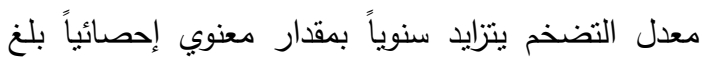

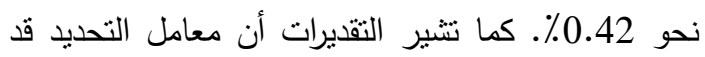
بلغ نحو 0.27 مما بعنى أن نحو 27\% من التغيرات في 


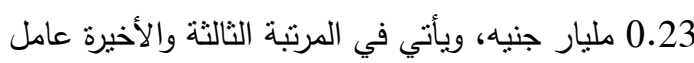
الاستهلاك العائلي حيث أن زيادة في الاستهلاك الك العائلي بمقدار مليار جنيه، يؤدي إلي نقص قيمة الدعم بحوالي

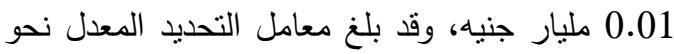

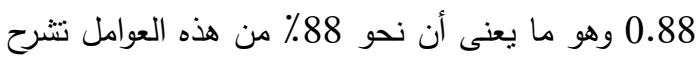
وتقسر مقدار التغير في قيمة الدعم لرغيف الخبز المصري.
النتائج أن عامل الصادرات الزراعية يحتل المرنبة الأولي

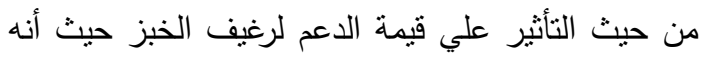

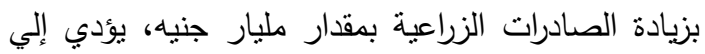

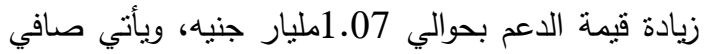
الاحتباطي النقدي الاجنبي في المرنبة الثانية، حيث أكدت

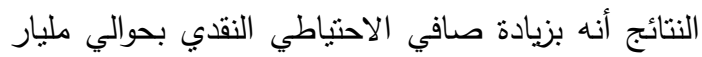

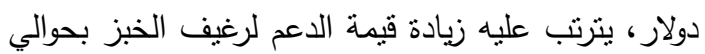

جدول رقم (6): الاتجاه الزمني العام لأهم المتغيرات الاقتصادية المؤثرة علي دعم رغيف الخبز المصري خلال الفترة (2015-2000)

\begin{tabular}{|c|c|c|c|c|}
\hline$F$ & $\mathbf{R}^{2}$ & المعادلة & المتغير & رقم المعادلة \\
\hline $33.02 * *$ & 0.70 & $\begin{array}{r}\widehat{\mathbf{Y}}_{\mathbf{t}}=4.21+0.18 \mathbf{t} \\
(14.02)^{* * *}(5.75)\end{array}$ & 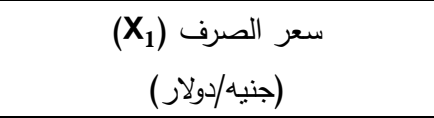 & 12 \\
\hline 230.95 & 0.94 & $\begin{aligned} \widehat{\mathbf{Y}}_{\mathrm{t}}= & 14.31+14.05 \mathrm{t} \\
& (1.60)^{* * *}(15.20)^{* * *}\end{aligned}$ & 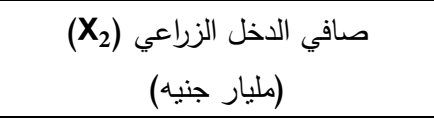 & 13 \\
\hline $139.18 * *$ & 0.91 & $\begin{aligned} \widehat{\mathbf{Y}}_{\mathbf{t}}= & -2.23+1.53 \mathbf{t} \\
& (-2.58)^{*}(17.08)^{* * *}\end{aligned}$ & 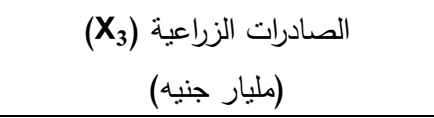 & 14 \\
\hline $39.68 * *$ & 0.74 & $\begin{aligned} & \widehat{\mathbf{Y}}_{\mathrm{t}}=-3.08+1.69 \mathrm{t} \\
&(-1.19)(6.30)^{* * *}\end{aligned}$ & 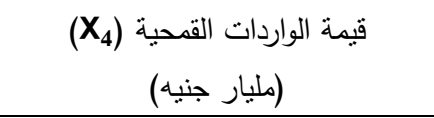 & 15 \\
\hline $47.91 \% *$ & 0.77 & $\begin{aligned} \widehat{\mathbf{Y}}_{\mathbf{t}}= & -4.93+2.44 \mathbf{t} \\
& (-1.45)(6.92)^{* * *}\end{aligned}$ & $\begin{array}{c}\text { عجز الميزان الزراعي (مليار جنية) } \\
\text { (مليه }\end{array}$ & 16 \\
\hline $16.86^{* *}$ & 0.55 & $\begin{array}{r}\widehat{\mathbf{Y}}_{\mathbf{t}}=118.10+193.22 t \\
(0.26) \quad(4.11)^{* *}\end{array}$ & 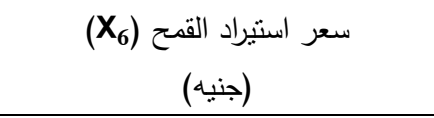 & 17 \\
\hline 1.27 & 0.08 & $\begin{array}{r}\widehat{\mathbf{Y}}_{\mathbf{t}}=17.24+0.46 \mathbf{t} \\
(4.35)^{* * *}(1.13)\end{array}$ & 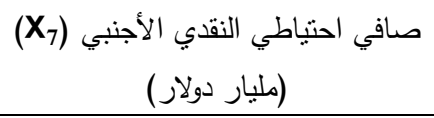 & 18 \\
\hline $111.34 * *$ & 0.89 & $\begin{array}{r}\widehat{\mathbf{Y}}_{\mathbf{t}}=-169.70+127.84 t \\
(-1.45) \quad(10.55)^{* * *}\end{array}$ & 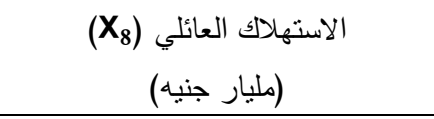 & 19 \\
\hline $5.37 *$ & 0.27 & $\begin{array}{r}\widehat{\mathbf{Y}}_{\mathbf{t}}=5.39+0.42 \mathbf{t} \\
(3.06)^{* *}(2.32)^{*}\end{array}$ & معدل التضخم (X) & 20 \\
\hline $14.92 * *$ & 0.52 & $\begin{array}{l}\widehat{\mathbf{Y}}_{\mathbf{t}}=11.21-0.17 \mathbf{t} \\
\quad(26.89)^{* *} *(-3.86)^{* *}\end{array}$ & سعر الخصم (X) & 21 \\
\hline $3211 *$ & 0.99 & $\begin{aligned} \widehat{\mathbf{Y}}_{\mathbf{t}}=61.49+1.59 t \\
\quad(266.17)^{* *}(56.67)^{* * *}\end{aligned}$ & 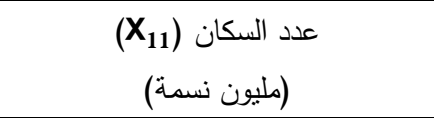 & 22 \\
\hline
\end{tabular}

حيث: القيمة التقديرية لأهم المتغيرات الاقتصادية المؤثرة علي قيمة الدعم لرغيف الخبز في المشاهدة أ.

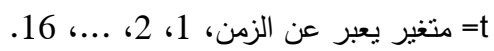
المصدر: نتائج الحاسب الآلي للبيانات الواردة بالجدول رقم (4) بالبحث. 
جلول (7): القياس الإحصائي لأهم المتغيرات الاقتصادية المؤثرة علي قيمة الاعم لرغيف الخبز المصري بالانحدار المرحلي خلال الفترة (2000-2015)

\begin{tabular}{|c|c|c|c|c|}
\hline$F$ & $\mathrm{R}^{/ 2}$ & النموذج القياسي & المستخدمة & 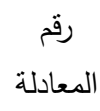 \\
\hline $38.94 * *$ & 0.88 & $\begin{aligned} \widehat{Y}_{\mathrm{t}}= & -0.93+1.07 \mathrm{X}_{4}+0.23 \mathrm{X}_{8}-0.01 \mathrm{X}_{9} \\
& (-0.56) \quad(4.13)^{* *}(3.01)^{* * *}(-2.58)^{*}\end{aligned}$ & الخطية & 23 \\
\hline 29.52 & 0.79 & $\begin{aligned} \log \widehat{Y}_{t}= & 6.15-0.48 \mathrm{X}_{11}+0.001 \mathrm{X}_{7} \\
& (6.41)^{* * *}(-5.24)^{* *}(3.03)^{* * *}\end{aligned}$ & لوغاريتمية & 24 \\
\hline $113.17 * *$ & 0.95 & $\begin{array}{l}\log \widehat{Y}_{t}=-5.24+0.71 \log X_{4}-0.001 \log X_{9}+1.42 \log X_{3} \\
(-2.68)^{*} \quad(2.88)^{* *} \quad(-6.07)^{* * *} \quad(2.65)^{* *}\end{array}$ & المزاريتمية & 25 \\
\hline
\end{tabular}

i القيمة التقديرية لقيمة الدعم رغيف الخبز بالمليار جنيه في المشاهدة

ا القيمة التقديرية لصافي الدخل الزراعي بالمليار جنيه في المشاهدة

القيمة التقديرية للصادرات الزراعية بالمليار جنيه في المشاهدةأ

i القيمة التقديرية لسعر استيراد القمح بالجنيه في المشاهدة

i القيمة التقديرية لصافي الاحتياطي النقدي الأجنبي بالمليار دولار في المشاهدئي

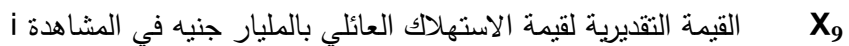

i القيمة التقديرية لسعر الخصم في المشاهدة

. 16 ... 2 ، $1=\quad$ i

المصدر: جمعت وحسبت من نتائج الحاسب الآلي للبيانات الواردة بالجدول رقم (4) بالبحث.

التأثثر علي قيمة الدعم لرغيف الخبز حيث أنه بزيادة قيمة الصادرات الزراعية بنحو 10٪، يؤدي إلي زيادة قيمة

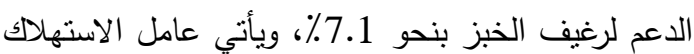

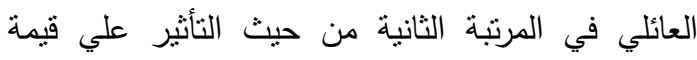

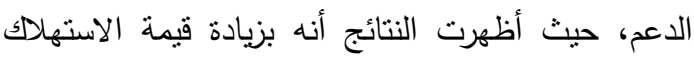
العائلي بنحو 10٪، يترنب عليه نقص قيمة الدعم لرغيف الخبز بنحو 0101\%. ويأني في المرتبة الثالثة والأخيرة عامل صافي الدخل الزراعي من حيث التأثير علي قيمة الدعم، حيث أظهرت النتائج أنه بزيادة قيمة صافي لرئ الدخل الزراعي بنحو 10٪، يترتب عليه زيادة قيمة الدعم لرغيف الخبز بنحو 14.2٪، وقد بلغ معامل التحديد المعدل نحو

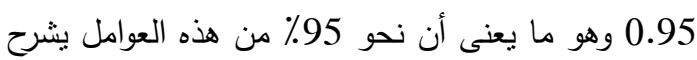

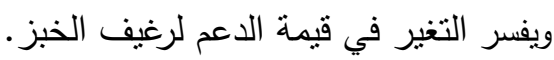

2- الصورة النصف لوغاريتمية:

أظهرت النتائج الواردة في المعادلة رقم (24)، أن

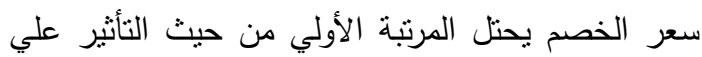
قيمة الدعم لرغيف الخبز حيث أنه بزيادة سعر الخصم

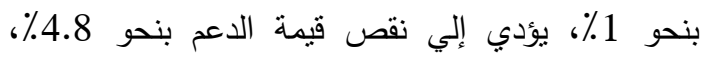

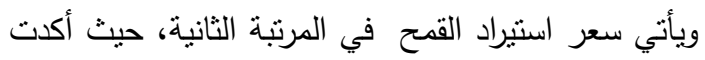

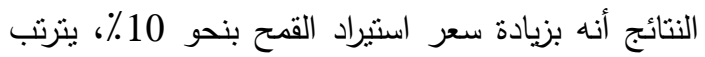
عليه زيادة قيمة الدعم لرغيف الخبز بنحو 0101٪، وقد باد

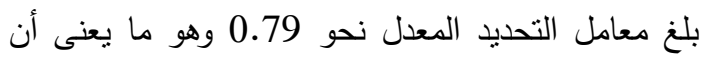
نحو 79٪ من هذين العاملين يشرحان ويفسران مقدار التغير في قيمة الدعم لرغيف الخبز الدصري.

3- الصورة اللوغاريتمية المزدوجة:

أظهرت النتائج الواردة بالمعادلة رقم (25)، أن عامل

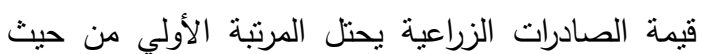


من 1990 إلى 2014، مركز دراسات الوحدة العربية،

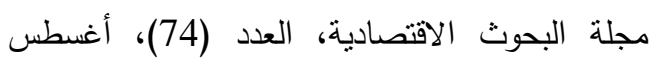

2- دعاء سمير محمد مرسي أحمد (دكتور)، دراسة

اقتصادية لمنظومة الخبز الجديدة على الدعم الغذائي

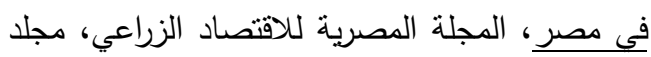

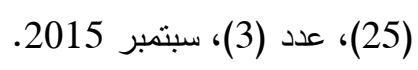

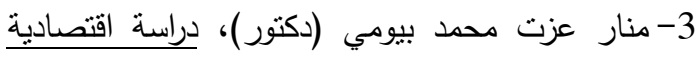

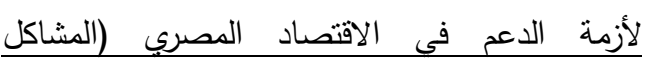

والحلول)، المجلة المصرية للاقتصاد الزراعي، مجلد

$$
\text { (24)، عدد (1)، مارس } 2014 .
$$

4- علاء الدين سعيد الثبراوي (دكتور)، أمل كامل أمين

(دكتور)، دراسة اقتصادية لتقييه عقد اتفاق إنتاج

الخبز البلدي الدعم 82٪ لعام لعام 2013، المؤتمر

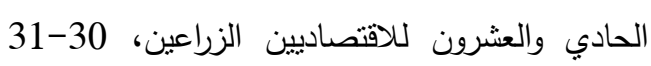

$$
\text { أكتوبر } 2013 .
$$

5- هاني سعيد عبد الرحمن الثتلة (دكتور) وآخرون، دائة

دراسة اقتصادية لبدائل مقترحة لخفض دعن دعم رغيف

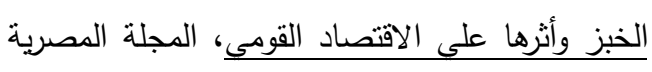

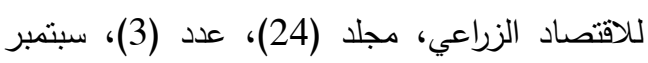

6- الجهاز المركزي للتعبئة العامة والاحصاء، الكتاب

$$
\text { الإحصائي، أعداد مختلفة. }
$$

7- A. S. Gold bergek, Econometric Theory, Johnvilley, Sons, Inc, New York, 1964.

8- Croxton and Cowden, Applied Statistics, Second Edition, Prentice Hall of India, New Delhi, 1960.

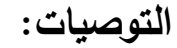

1- إعادة هيكلة الدعم الحكومي الدصري في إطار

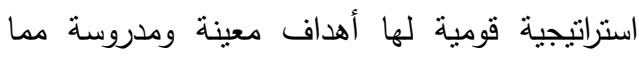

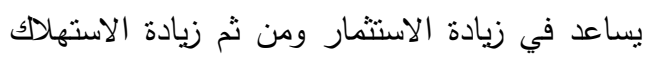
النهائي الداعم لزيادة الاستثمار المحلي والأجنبي.

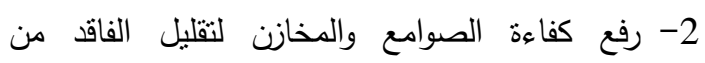

محصول القمح، والتوسع في خلط القمح بدقيق الذرة

لتوفيره لكافة المواطنين.

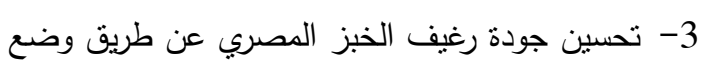

المواصفات الفنية للخبز البلدي المدعم علي أن يقوم لقدي

بإعداده القطاع الخاص ثم تقوم الحكومة بشرائه وبيعه

بأسعار مدعمة للمستهلكين.

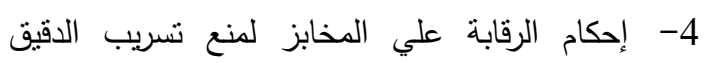

المدعم وبيعه في السوق السوداء.

5- نوعية المواطنين عن طريق تغيير وترشيد عادات

الاستهلاك للخبز - توعة الكوان

6- إنثاء قاعدة بيانات دقيقه للحائزين علي بطاقات التموين لمنع الازدواجية وضبط منظومة الدعم.

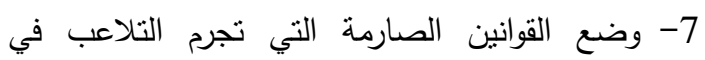

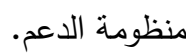

8- تتديد الرقابة علي الأجهزة المعنية علي المطاحن لضمان جودة الدقيق ووصوله لمستحقيه.

9- وضع الضوابط التي تمكن مفتشي التموين من الرقابة المحكمة علي المخابز التي تنتارك في الدعم.

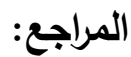

1-زينب توفيق السيد عليوة (دكتور)، تقييم أثر الدعم

الحكومي في النمو الاقتصادي في مصر خلال الفترة 


\title{
AN ECONOMIC STUDY FOR IMPORTANT ECONOMIC VARIABLES AFFECTING EGYPTIAN BREAD SUBSIDY
}

\author{
M. A. EISayed
}

Dept. of Economic \& Rural Development, Fac. of Environ. Agri. Sc., Arish University

\begin{abstract}
The Subsidy issue is considered one of the important issues for many countries in different political, social and economic systems, but the developing countries for many reasons, are considered the most in need of subsidy systems in order to combat poverty. The continued increase in the bread subsidy increased its value from L.E 1500 million in 2000 to L.E 9100 million in 2015.

The research aims to study the most important factors affecting the bread subsidy and to determine the most important economic and production variables for wheat crop, to study the relative importance of bread subsidies compared with the total food subsides.

The results indicate that the bread subsides reached L.E 8600million in 2000, while the total food subsides reached L.E 16800 million in 2009, the relative importance of the value of bread subsidies about $71.4 \%$, compared to $43.5 \%$ from the total food subsides.

The results indicated that the most important variable affecting the value of bread subsidy were the agricultural exports, the net monetary reserves and the family consumption.

The semi-logarithmic function results indicated that the discount rate came in the first rank, the increase in discount rate by $1 \%$ leads to decrease the subsidy by $4.8 \%$. Wheat import price came in the second rank. The increase in wheat import price by $10 \%$ leads to increase bread subsidy by $0.01 \%$.

The double log function results indicated that the family consumption and the net farm income were the most important variables affecting the value of bread subsidy.

Research has recommended raising the efficiency of the silos and warehouses to reduce wastage of wheat crop, and the expansion of mixing wheat flour with corn flour corn to be provided to all citizens, educate citizens by changing and rationalizing the consumption habits of bread, to observe and control over the organs concerned to mills to ensure strict quality of and access to those who deserve it, put the controls that enable inspectors Supply ministry to control the bakeries that are involved in the subsidy, put strict laws that criminalize the manipulation of the support system.
\end{abstract}

Key words: Egyptian Bread, Wheat crop, Subsidy. 